\title{
NOVOS DEBATES SOBRE O “ÔNUS" DA PROVA ACORDOS E DESACORDOS ENTRE A DOUTRINA SOBRE O TEMA ${ }^{1}$
}

\author{
NEW DEBATES ABOUT THE "BURDEN" OF PROOF. AGREEMENTS AND \\ DISAGREEMENTS AMONG THE JURISPRUDENCE ABOUT THE MATTER.
}

Vitor de Paula Ramos

\section{RESUMO}

No presente trabalho o autor pretende seguir os debates a respeito do ônus da prova. Assim, na primeira parte apresenta um resumo a respeito das suas ideias apresentadas em obras anteriores. A seguir, apresenta as ideias principais dos autores que escreveram sobre o tema nos últimos anos. Por fim, apresenta diálogo crítico com tais ideias.

Palavras-chaves: Ônus da Prova; Deveres de Prova; Direito Probatório; Raciocínio probatório.

\section{ABSTRACT}

In the present article the author intends to continue the debates about the burden of proof. Being so, in the first part he presents a summary of the ideas he has presented on his past works. Following this, he presents the main ideas of authors that have written about it in the last years. In the final part, he presents a critical dialogue with those ideas.

Keywords: Burden of proof; Duties of proof; Evidence law; Evidential reasoning.

\section{INTRODUÇÃO}

O ônus da prova é um tema clássico, razão pela qual foi objeto de múltiplas análises monográficas, como as de Augenti ${ }^{2}$, Micheli $^{3}$, Rosenberg ${ }^{4}$ e Verde ${ }^{5}$. Nas últimas décadas, o interesse pela matéria se renovou a partir das ideias de Peyrano ${ }^{6}$ sobre o chamado ônus dinâmico da prova - algo que não só foi objeto de intenso debate na doutrina ${ }^{7}$, como também foi recepcionado por muitas legislações em toda América Latina ${ }^{8}$.

Em 2015, publiquei minha obra "Ônus da Prova no Processo Civil: Do Ônus ao Dever de Provar"”, em cuja segunda edição, de 2018, critiquei a doutrina tradicional do ônus da prova e, acima de tudo, os chamados ônus dinâmicos da prova, propondo uma nova forma de pensar sobre

\footnotetext{
1 Texto originalmente publicado em JOBIM, Marco Félix; PEREIRA, Rafael Caselli. Fundamentos Objetivos e o Novo Processo Civil Brasileiro. Londrina: Thoth, 2021.

2 AUGENTI, Giacomo Primo. L’Onere della Prova. Roma: Foro Italiano, 1932.

MICHELI, Gian Antonio. L'Onere della Prova. Padova: CEDAM, 1942.

4 ROSENBERG, Leo. La carga de la prueba. Trad. Ernesto Krotoschin. Buenos Aires: Ediciones Jurídicas Europa América, 1956.

5 VERDE, Giovanni. L'Onere della Prova nel Processo Civile. Napoli: Jovene, 1974.

6 Um resumo dessas ideias pode ser visto em PEYRANO, Jorge. "La carga de la prueba. Los criterios de valoración y los fundamentos de la decisión sobre quién está en mejores condiciones de probar”. In: OTEIZA, Eduardo (org.). La prueba en el proceso judicial.

7 Veja-se, por exemplo: CARPES, Artur. O Ônus Dinâmico da Prova. Porto Alegre: Livraria do Advogado, 2010; MACÊDO, Lucas Buril de; PEIXOTO, Ravi. Ônus da Prova e Sua Dinamização. 2. ed. Salvador: JusPodivm, 2016; CARPES, Artur. Ônus da Prova no Novo CPC. Do Estático ao Dinâmico. São Paulo: RT, 2017.

8 No caso do Brasil, para dar um exemplo, no art. 373, § 1. ${ }^{\circ}$ do CPC de 2015.

9 PAUlA RAMOS, Vitor de. Ônus da Prova no Processo Civil. 2. ed. São Paulo: RT, 2018.
} 


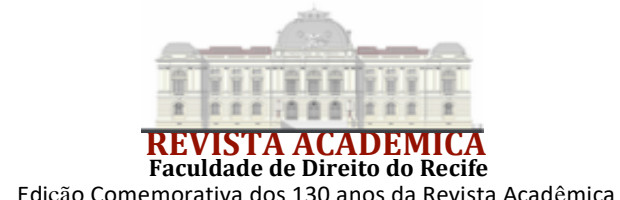

as atividades e o resultado probatório ${ }^{10}$.

Em 2019, o debate seguiu se intensificando, com a publicação do livro "Contra la carga de la prueba ${ }^{11}$, de Jordi Ferrer, Jordi Nieva Fenoll e Leandro Giannini, com prólogo de Michele Taruffo. Nesse os autores, apresentam posições bastante críticas à doutrina tradicional do ônus da prova, fazendo propostas. Mais recentemente, em 2020, Daniel Mitidiero publicou um ensaio chamado "O ônus da Prova e seus Inimigos" propostas sobre o tema.

A ideia do presente artigo, portanto, é prosseguir com os debates de ideias e dialogar com as ideias apresentadas pelos escritos mais recentes. Na primeira parte farei um resumo das ideias que apresentei no Ônus da Prova no Processo Civil. Na segunda, apresentarei as ideias de cada um desses autores junto com alguns comentários críticos. E, na terceira, tentarei desenvolver o tema, formulando "críticas das críticas das críticas", por assim dizer.

\section{AS IDEIAS QUE DEFENDI EM "ÔNUS DA PROVA NO PROCESSO CIVIL"}

A primeira parte da minha obra ${ }^{13}$ tinha um objetivo central: demonstrar que, partindo das premissas de um processo epistemologicamente orientado, a busca pela tendencial completude do material probatório deve ser um objetivo institucional. Sustentei, em outras palavras, que, aumentando-se as provas relevantes aportadas a um conjunto probatório de um processo concreto, aumenta também a qualidade epistêmica da decisão sobre os fatos ${ }^{14}$.

Por sua vez, a segunda parte começava apresentando as ideias da doutrina tradicional sobre o ônus da prova, de acordo com que essa teria dois aspectos: um objetivo ${ }^{15}$, que seria uma regra de juízo e, portanto, teria relação com o juiz; e outro subjetivo, que se referiria às partes, como um "estímulo" para que apresentassem provas ao processo ${ }^{16}$. Não obstante, o ônus da prova, de acordo com a doutrina tradicional, seria diferente dos outros ônus, pois não comportaria "necessariamente um prejuízo, mas apenas o risco de um prejuízo, tendo em vista que a produção da prova não está diretamente ligada ao resultado favorável, mas apenas à maior chance de convencimento do juiz" ${ }^{17}$.

$\mathrm{Na}$ sequência descrevi como a doutrina chegou à conclusão de que o ônus "fixo", em muitos casos, não servia para aportar as provas disponíveis ao processo, razão pela qual propuseram-se, na doutrina, as chamadas inversões do ônus probatório, assim como os denominados ônus dinâmicos da prova. A ideia dessas seria, em resumo, alterar (dinamizar) o ônus para a parte que detém a prova, fazendo, supostamente, com que ela aportasse a prova em juízo.

Antes de apresentar as críticas à doutrina tradicional, expus algumas bases teóricas. Em primeiro lugar, com base nas críticas de Gavazzi ${ }^{18}$, propus o abandono da amplamente aceita

${ }^{10}$ Com uma proposta semelhante na Argentina, veja-se CAZAUX, Diego. "Carga de la prueba, bases y propuestas para la reformulación del concepto. De la carga al deber de probar. Análisis crítico del caso argentino". Revista Iberoamericana de Derecho Procesal, v. 10, p. 183-219, 2019.

11 NIEVA FENOLL, Jordi; FERRER BELTRÁN, Jordi; GIANNINI, Leandro. Contra la carga de la prueba. Madrid: Marcial Pons, 2019.

12 MITIDIERO, Daniel. “O Ônus da Prova e seus Inimigos”. Revista de Processo, v. 306, p. 17-47, ago. 2020.

13 PAUla RAMOS, Vitor. Ônus da Prova no Processo Civil. Do Ônus ao Dever de Provar. 2. ed. São Paulo: RT, 2018. p. 25-50.

14 Para as referências bibliográficas e os autores de cujos pensamentos parti, veja-se: a PAULA RAMOS, Vitor. Ônus da Prova no Processo Civil. Do Ônus ao Dever de Provar. 2. ed. São Paulo: RT, 2018. p. 44.

15 VERDE, Giovanni. L'Onere della Prova nel Processo Civile. Napoli: Jovene, 1974: 118; CARPES, Artur. Ônus da Prova no Novo CPC..., cit., p. 40.

16 CARPES, Artur. Ônus Dinâmico da prova, cit., p. 54; CARPES, Artur. Ônus da prova no Novo CPC..., cit., p. 46. MACÊDO, Lucas Buril de; PEIXOTO, Ravi. Ônus da prova e sua dinamização. 2. ed. Salvador: JusPodivm, 2016. p.87.

17 MONIZ DE ARAGÃO, Egas Dirceu. “Direito à Prova”. Revista de Processo, São Paulo, v. 39, p. 98 et seq., jul. 1985.

18 GAVAZZI, Giacomo. L'Onere - Tra la Libertà e L'Obbligo. Torino: Giappichelli, 1970. p. 83-84. 


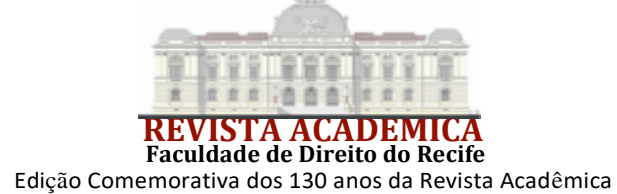

definição Carneluttiana de ônus - segundo a qual o ônus seria um vínculo à vontade baseado no interesse próprio, ao passo que o dever seria um vínculo baseado em interesse alheio $-{ }^{19}$. Gavazzi criticava, em minha opinião com razão, a concepção Carnelutiana como individualista ${ }^{20}$, demonstrando que o ônus atua sempre - ainda que por vezes de modo mediato - em função de um interesse público ${ }^{21}$. Ademais, propus abandonar a ideia de "interesse", utilizada também por Gavazzi, de modo que o ônus e o dever se definiriam da seguinte forma ${ }^{22}$ :

I. O ônus, em resumo, seria uma situação passiva subjetiva com sujeição fraca, que descreve um comportamento (positivo ou negativo) "apreciado" pelo Direito; dá ao sujeito sobre o qual recai a possibilidade de escolher entre agir ou não de acordo com o comportamento (positivo ou negativo) "apreciado". Ao agir "contra" o comportamento previsto na regra que estabelece o ônus o sujeito não comete uma ação ou omissão contrária ao Direito e, portanto, não se configura um ilícito; a consequência de o comportamento não ser adotado está na própria regra, no resultado "prometido" para cada escolha. É dizer: "se escolher o comportamento A terás B"; "se escolher o comportamento não A, não terás B".

II. O dever, resumidamente, seria uma situação subjetiva passiva com sujeição radical, que descreve um comportamento (positivo ou negativo) "exigido" pelo Direito, não dando ao sujeito obrigado a possibilidade de escolher licitamente entre agir ou não de acordo com o comportamento (positivo ou negativo); tão somente exige o cumprimento. Ao agir "contra" o comportamento previsto na regra que estabelece o dever o sujeito cometerá uma ação ou omissão contrária ao Direito, configurando-se assim um ilícito; ao sujeito que não adotar o comportamento serão impostas sanções diretas ou indiretas, penalidades, técnicas coercitivas (por exemplo, multa diária) etc.; é dizer, o Direito utilizará sua força imperativa para fazer com que se adote o comportamento exigido.

Em segundo lugar ${ }^{23}$, sustentei que a processualística clássica do século XX escreveu sobre o ônus da prova em um contexto cultural diferente do atual; nesse, defendia-se que o princípio dispositivo incluiria o direito à prova, de modo que o juiz não deveria ter atividades probatórias algo que vai ilustrado pela frase de Chiovenda de que o "magistrado julga com base nas provas produzidas: pior para as partes se essas são insuficientes" 24 . A doutrina dessa época, de fato, como se demonstrou mais tarde ${ }^{25}$, havia recebido equivocadamente o brocardo iudex debet secundum allegata et probata com a indevida inclusão da palavra "partium" ao final ${ }^{26}$, que transformava o que era uma proibição de conhecimento privado por parte do juiz em uma proibição de que o juiz tivesse poderes probatórios. O próprio Chiovenda assim o demonstrava, afirmando que a "teoria do ônus da prova está estreitamente conectada à conservação do princípio dispositivo no processo, com relação à apuração dos fatos. Em um sistema em que se admitisse a investigação de ofício da veracidade dos fatos, a divisão do ônus da prova não teria sentido ${ }^{27}$ ".

Sobre esses pilares, e considerando a necessidade de melhorar a completude do material probatório, formulei quatro críticas à doutrina tradicional ${ }^{28}$ :

${ }^{19}$ CARNELUTTI, Francesco. Sistema del Diritto Processuale Civile, Funzione e Composizione del Processo. Padova: CEDAM. 1936, p. 55. v. 1.

20 GAVAZZI, Giacomo, op. cit., p. 53.

21 Idem, p. 68.

22 PAULA RAMOS, Vitor de. Ônus da Prova no Processo Civil, p. 70.

${ }^{23}$ PAULA RAMOS, Vitor de. Ônus da Prova, p. 74-80.

24 CHIOVENDA, Giuseppe. Principii di Diritto Processuale Civile. Napoli: Jovene, 1965. p. 730.

25 PICÓ I JUNOY, Joan. El juez y la prueba. Estudio de la errónea recepción del brocardo Iudex Iudicare Debet Secundum Allegata et Probata, non secundum conscientiam y su repercusión actual. Barcelona: Bosch, 2007.

26 MICHELI, Gian Antonio. L'Onere della Prova. Padova: CEDAM, 1942. p. 161.

27 CHIOVENDA, Giuseppe, op. cit., p. 796.

28 PAULA RAMOS, Vitor de. Ônus da Prova, p. 81-100. 


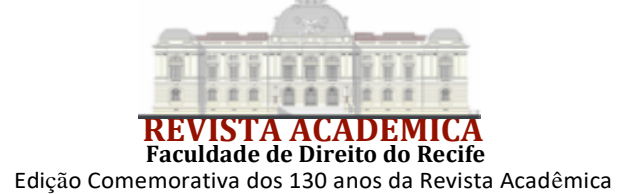

i. O ônus, seja dinâmico ou fixo, por sua própria natureza, sempre dá ao sujeito a possibilidade de escolher se quer levar, ou não, uma prova a juízo;

ii. $\mathrm{O}$ suposto aspecto subjetivo, dirigido às partes, tal como é formulado, não é um ônus, nem é autônomo, pois o resultado da demanda é determinado pela corroboração das hipóteses de fato e dita corroboração não tem relação direta, nem automática, com a atividade de uma parte (o juiz tem poderes de instrução e a parte contrária pode aportar a juízo um elemento de prova que a prejudique).

iii. O chamado aspecto objetivo, dirigido ao juiz, não é um ônus, mas sim um dever de que esse julgue de acordo com a regra de juízo em caso de insuficiente corroboração das hipóteses de fato; é uma regra de desempate;

iv. As dinamizações do ônus não estimulam verdadeiramente as partes a levarem aos autos provas contrárias aos seus interesses, pois sempre seguirá sendo melhor não levar uma prova a juízo e ter o risco de perder a demanda, do que a levar e ter a "certeza". Na segunda edição de meu livro, incorporei uma busca jurisprudencial $^{29}$ que demonstra que, no Brasil, até 2018 (quando publicada a segunda edição), somente se havia utilizado a distribuição dinâmica do ônus da prova em dez casos e em nenhum desses haviam sido aportadas novas provas uma vez procedida a dinamização do ônus.

Desse modo, minha proposta de reconstrução foi separar a atividade probatória do resultado.

Sobre a atividade probatória, defendi que o objetivo de um sistema probatório deve ser aumentar o máximo possível a completude tendencial do material probatório, dentro dos limites impostos pelos recursos fianceiros, pelo tempo, pelo respeito aos direitos fundamentais etc. Para tanto, considerando que, hoje em dia, o juiz pode ordenar a produção de uma prova, um terceiro pode trazê-la, ou, até mesmo, a parte contrária, propus afastar a ideia de que toda a atividade probatória se resumisse à atividade das partes. Com relação a essas últimas sugeri o desenvolvimento de deveres substanciais e processuais de prova ${ }^{30}$, pois os deveres, diferentemente do ônus, não dão uma opção lícita ao sujeito obrigado. Assim, um sujeito obrigado por uma regra substancial a conservar uma prova e a aportar quando determinado não tem a opção de se negar a assim proceder. Dessa forma, com a juntada desta prova, aumenta-se a qualidade do material probatório.

Sobre a prova como resultado, defendi ${ }^{31}$ que a regra que costuma ser denominada "ônus da prova", em realidade, é um dever do juiz, a ser utilizada em casos em que não se alcança o standard probatório aplicável. Quando há prova suficiente, o juiz aplica diretamente o direito material; quando não há prova suficiente (considerando como suficiente o standard aplicável), o juiz não tem elementos suficientes nem para decidir que $\operatorname{sim}$ nem que não (por exemplo, nem que João causou danos à Maria, nem que não causou). Nesse caso, a regra do art. 373 do CPC impõe ao juiz um dever que pode ser resumido da seguinte forma: "se não alcançado o standard, juiz, julgue desta forma" 32 .

\section{$3 \quad$ NOVAS PROPOSTAS DA DOUTRINA}

Nos recentes debates sobre o ônus da prova, cada autor apresentou uma forma de ver o problema, de modo que, a seguir, optei por trabalhar com as ideias de cada autor de modo global.

\footnotetext{
${ }^{29}$ PAULA RAMOS, Vitor de. Ônus da Prova..., p. 133.

${ }^{30}$ PAULA RAMOS, op. cit., p. 111.

${ }^{31}$ PAULA RAMOS, op. cit., p. 122.

${ }^{32}$ Como referi na nota 96 do livro (PAULA RAMOS, Vitor, p.127), essa ideia sobre o direito material foi fruto de um intercâmbio de ideias com Jordi Ferrer em 14 de junho de 2013 em Girona.
} 


\subsection{A. JORDI NIEVA FENOLL ${ }^{33}$}

Dentre os três autores de "Contra la carga de la prueba", Nieva Fenoll é quem diretamente se manifesta contra a existência dessa instituição, considerada pelo autor uma "relíquia histórica". Nieva defende que a passagem de um sistema legal de provas a um de livre valoração teria feito com que se perdesse "toda a utilidade que até então havia tido o ônus da prova" 34 , já que "o sistema do ônus da prova estava configurado seguindo a pauta do sistema de prova legal, a ponto de com esse se confundir" 35 . A recepção equivocada do brocardo secundum allegata et probata - que demonstra que, em realidade, se tratava de uma tentativa dos "séculos XII-XIII de controlar a arbitrariedade judicial no uso de seu próprio raciocínio, limitando os materiais de juízo àquele mostrado no processo" $" 36$ - teria feito com que parte da doutrina tentasse salvar o instituto.

Em sua proposta sobre a atividade probatória, o autor sustenta a inconveniência da inversão do ônus da prova, considerando que "é injusto inferir, por si só, que quem não tem uma prova não tem razão, ou pior, que quem não leva a prova ao processo é porque a está ocultando, porque seu conteúdo lhe é desfavorável" ${ }^{\prime 3}$. Sobre o resultado probatório, propõe diretamente eliminar a regra de ônus da prova: quando resta "algum fato ignoto, e ante a necessidade de se evitar um non liquet (...), o que se deve fazer é simplesmente não lhe considerar provado" "38. E conclui: "[n]ão é que não tenha ocorrido o fato; o que ocorreu foi que se tentou provar e não foi possível demonstrar nem que esse existiu, nem que não existiu. E, diante dessa situação, não se pode aplicar a norma jurídica que parte de sua existência" 39 .

Com relação à atividade probatória, concordo com Nieva Fenoll nas críticas que faz à inversão, ou dinamização, do ônus probatório. Concordo também com o autor em relação à importância que a recepção equivocada do brocardo secundum allegata et probata teve nas múltiplas tentativas da doutrina de salvar a teoria do ônus da prova da forma como estava proposta. Como comentei no capítulo anterior, curiosamente, nesse sentido, o próprio Chiovenda dizia que em "um sistema em que se admitsse a investigação de ofício da veracidade dos fatos, a distribuição do ônus da prova não teria significado" 40 . A questão, a meu ver ${ }^{41}$, reside em que o desenvolvimento teórico do ônus da prova (sobretudo com relação ao que mais interessa em nossos sistemas processuais, a partir da doutrina italiana do século XX) se deu em um contexto em que o processo vinha pensado como algo de interesse exclusivo das partes - algo que, como corretamente demonstra Nieva Fenoll ${ }^{42}$, mudou hoje em dia.

Com relação ao resultado probatório, concordo com Nieva Fenoll em que o chamado ônus objetivo "nada tem a que ver com um ônus"43. De fato, na minha opinião, trata-se de um dever ${ }^{44}$, que se dirige não às partes, mas, sim, ao juiz ${ }^{45}$ : o dever de julgar de acordo com a regra em caso de insuficiência probatória; é dizer, quando a prova não supera o standard probatório aplicável ao caso. Sem embargo, discordo de Nieva Fenoll quando afirma que a regra que determina como se

${ }^{33}$ NIEVA FENOLL, Jordi. "La carga de la prueba: una reliquia histórica que debería ser abolida". In: NIEVA FENOLL, Jordi; FERRER BELTRÁN, Jordi; GIANNINI, Leandro. Contra la carga de la prueba. Madrid: Marcial Pons, 2019. p. 23-52.

${ }^{34}$ NIEVA FENOLL, p. 35.

${ }^{35}$ NIEVA FENOLL, Jordi, op. cit., p. 35

${ }^{36}$ NIEVA FENOLL, op. cit., p. 37.

${ }^{37}$ NIEVA FENOLL, op. cit., p. 45-46.

${ }^{38}$ NIEVA FENOLL, op. cit., p. 43-44.

${ }^{39}$ NIEVA FENOLL, op. cit., p. 44.

${ }^{40}$ CHIOVENDA, Giuseppe, p. 796.

${ }^{41}$ PAULA RAMOS, Vitor, p. 74.

${ }^{42}$ NIEVA FENOLL, Jordi, op. cit., p. 43; PAULA RAMOS, op. cit., p. 74-81; TARUFFO, Michele. "Casi una introducción”. In: NIEVA FENOLL, Jordi; FERRER BELTRÁN, Jordi; GIANNINI, Leandro. Contra la carga ..., op. cit.

${ }^{43}$ NIEVA FENOLL, op. cit. p. 43

${ }^{44}$ PAULA RAMOS, Vitor, op. cit., p. 90.

${ }^{45}$ PAULA RAMOS, Vitor de, op. cit., p. 122. 


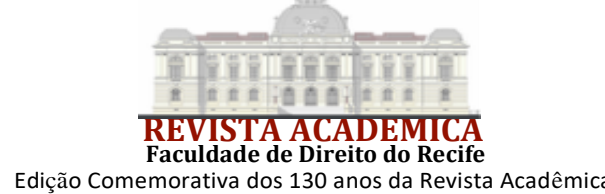

deve julgar quando não há provas suficientes não tenha utilidade.

Apesar de concordar com o autor sobre em que, quando não há provas suficientes de um fato, não é possível "demonstrar nem que existe [o fato] nem que não existe" ${ }^{46}$, acredito que não se pode, justamente por isso, afirmar que, não havendo provas suficientes, a solução automaticamente deveria ser o reconhecimento judicial de que a parte a quem a regra material beneficiaria não tem razão. Definitivamente, se João acusa Maria de haver causado danos ao seu veículo e, ao final do litígio, não há provas, a consequência, como reconhece o próprio Nieva Fenoll, seria a impossibilidade de dizer-se que Maria causou danos ao veículo de João, e também a impossibilidade de se dizer que Maria não causou tais danos. Então, por que o sistema automaticamente deveria dar razão a Maria? Por que essa deveria ser uma consequência do próprio direito material?

A regra de direito material, que no caso brasileiro se encontra no art. 927 do CC, contém uma dupla instrução dirigida ao juiz: quem causa danos a outrem tem o dever de indenizar, quem não causa danos a outrem não pode ser obrigado a indenizar. Se há provas suficientes de que Maria causou danos a João, o juiz deve aplicar o direito material e julgar procedente a demanda. Se há provas suficientes de que Maria não causou danos a João - por exemplo, porque se demonstra que o veículo de João não sofreu danos, ou que, em realidade, foi Pedro quem causou os danos, e Maria se encontrava longe do lugar em que ocorreram os fatos -, o juiz também deve aplicar o direito material e julgar improcedente a demanda. Quando não há provas, ao não ser possível nem afirmar nem negar a hipótese, têm razão Mitidiero e Ferrer Beltrán: o primeiro quando diz que, diante da falta de prova suficiente, o direito material não dá respostas ${ }^{47}$, sendo "inadequado tratar a alegação de fato duvidosa como falsa, ou presumivelmente falsa"48; e o segundo quando afirma que "a pergunta de quem perde quando não há provas suficientes" 49 segue sendo necessária.

A falta de prova, nesse caso, funciona como quando um médico deve decidir se um paciente fraturou a mão ou não se baseando em uma radiografia desfocada ${ }^{50}$. O médico não tem condições de afirmar se há ou não uma fratura, não podendo, nesse caso, simplesmente encaminhar o paciente para casa sem mais, pois isso significaria, consciente ou inconscientemente, uma conclusão pela inexistência de fratura.

Do ponto de vista epistêmico, não é o mesmo uma decisão que reconheça que não há uma fratura e uma decisão que reconheça que não há provas sobre a (in)existência da fratura. Do mesmo modo, no Direito, se simplesmente se afirma que, diante da falta de provas dos suportes fáticos do art. 927 do CC, Maria tem razão, estar-se-ia concluindo no sentido de que a prova de que Maria não causou danos e a falta de provas sobre a (in)existência dos danos teriam a mesma consequência. A regra material, não obstante, protege não somente quem sofre danos, mas também quem não causa danos, que tem direito a uma sentença de improcedência.

Apesar de, não pensar, ao contrário do que sustenta Nieva Fenoll, que se trate de uma consequência automática, nem de uma exigência lógica do direito material, não vejo problema em que um sistema jurídico concreto decida usar o critério proposto pelo autor para os casos de insuficiência. De qualquer sorte, na minha opinião, tratar-se-á de uma regra de desempate como qualquer outra: da mesma forma que o direito possa escolher que, diante da falta de provas, deverá ganhar o consumidor, o mais velho, o Ministério Público em casos ambientais, a defesa em casos penais, etc., também pode estabelecer que deverá perder a demanda a parte a quem beneficiaria a regra material em questão, cujos fatos não tiverem sido provados em juízo. Isso, entretanto, não será uma consequência natural do direito material, mas sim uma regra que imporá um dever ao juiz de julgar de um modo determinado em caso de insuficiente corroboração dos fatos.

\footnotetext{
${ }^{46}$ NIEVAL FENOLL, Jordi, p. 44.

${ }^{47}$ MITIDIERO, Daniel. “O Ônus da Prova e Seus Inimigos”. Revista de Processo, v. 306, ago. 2020.

${ }^{48}$ Idem.

${ }^{49}$ FERRER BELTRÁN, Jordi, p. 73-74, n. 44.

${ }^{50}$ Utilizei esse exemplo em PAULA RAMOS, Vitor de, p. 127.
} 


\subsection{B. JORDI FERRER BELTRÁN ${ }^{51}$}

Ferrer Beltrán defende que as chamadas duas dimensões do ônus da prova, a objetiva e a subjetiva, em realidade são "regras totalmente diferentes, que se dirigem a sujeitos diversos, têm uma força normativa distinta e regulam atividades probatórias diferentes" ${ }^{", 2}$, de modo que não seria possível sustentar que uma seria consequência da outra ${ }^{53}$. Acrescenta o autor que a formulação de uma regra técnica a partir de uma regra jurídica (como "se queres fazer um testamento hológrafo deves ter duas testemunhas") não duplica o universo normativo, pois as regras técnicas "não são, em si mesmas, pertencentes ao Direito, nem uma segunda dimensão das normas jurídicas a partir dais quais são formuladas" ${ }^{4}$

Ademais, Jordi Ferrer defende que o grau de exigência probatória previsto para considerar um fato provado é satisfeito, ou não, "em função do que se infere do conjunto das provas aportadas" 55 , sendo possível que um fato extintivo resulte provado por "efeito das provas apresentadas pelo autor" ${ }^{\prime \prime}$. Com o princípio da aquisição processual ou de comunidade da prova não faria sentido falar da dimensão subjetiva do ônus da prova.

Partindo dessas premissas, Ferrer Beltrán critica o ônus dinâmico da prova e sustenta três razões: (i) por considerar uma falácia de afirmação pensar que para incentivar o aporte de provas pela parte que tem melhores condições de provar deveríamos lhe atribuir o ônus da prova - pois a inversão do ônus da prova não dá incentivos adequados, por exemplo, para que um médico demandado por responsabilidade civil profissional aporte a juízo provas em seu poder que demonstrem sua negligência -; (ii) por agrupar indevidamente atividade e resultado (por exemplo, aportar o prontuário médico e provar que não houve negligência; (iii) porque o autor entende que "inverter o ônus da prova não é outra coisa, senão modificar o suporte fático da norma material" o que causa insegurança jurídica.

Assim, o autor propõe que, para a atividade probatória, se estabeleçam genuínos deveres de aporte, inclusive com mecanismos como o discovery estadunidense ${ }^{58}$. Ao contrário de Nieva Fenoll, Ferrer Beltrán sustenta que a chamada dimensão objetiva é necessária, pois segue sendo imprescindível "a pergunta sobre quem perde se não houver provas suficientes"

Minhas ideias e as de Jordi Ferrer têm muito em comum.

Ferrer Beltrán e eu, como já escrevi no passado ${ }^{60}$, estamos de acordo sobre a inexistência da dimensão subjetiva do ônus da prova e sobre o fato de que as regras técnicas (muitas das quais, parte da doutrina costuma denominar ônus imperfeitos) não são regras jurídicas, mas sim necessidades práticas ${ }^{61}$. Também concordamos sobre a inexistência de vinculação entre a atividade de uma parte e o resultado: uma parte que não leva provas a juízo ${ }^{62}$, ou que até mesmo decide não participar do processo, pode, assim mesmo, ganhar; e alguém que aporta muitas provas pode perder, pois o processo civil não é uma "competição de boas intenções" ${ }^{63}$, e a prova não é uma

${ }^{51}$ FERRER BELTRÁN, Jordi. "La carga dinámica de la prueba. Entre la confusión y lo innecesario". In: NIEVA FENOLL, Jordi; FERRER BELTRÁN, Jordi; GIANNINI, Leandro. Contra la carga de la prueba. Madrid: Marcial Pons, 2019. p. 23-52.

${ }^{52}$ FERRER BELTRÁN, Jordi, op. cit., p. 70.

${ }^{53}$ FERRER BELTRÁN, Jordi, op. cit., p. 70.

${ }^{54}$ FERRER BELTRÁN, Jordi, op. cit., p. 71.

${ }^{55}$ FERRER BELTRÁN, Jordi, op. cit., p. 72.

${ }^{56}$ FERRER BELTRÁN, Jordi, op. cit., p. 72.

${ }^{57}$ FERRER BELTRÁN, Jordi, op. cit., pp. 78-79.

${ }^{58}$ FERRER BELTRÁN, Jordi, op. cit., p. 83.

${ }^{59}$ FERRER BELTRÁN, Jordi, op. cit., p. 73-74, no 44.

${ }^{60}$ PAULA RAMOS, Vitor de, p. 87.

${ }^{61}$ PAULA RAMOS, Vitor de, op. cit., p. 89.

${ }^{62}$ PAULA RAMOS, Vitor de, p. 88

${ }^{63}$ PAULA RAMOS, Vitor de, op. cit., p. 89. 


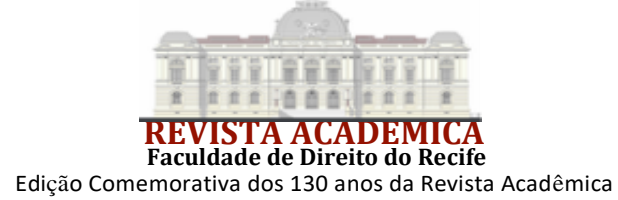

medida quantitativa ${ }^{64}$.

Do mesmo modo, Ferrer Beltrán e eu estamos de acordo em que o resultado da demanda, quando há provas suficientes, é determinado "em função do que se infere do conjunto de provas aportadas" $" 65$; quando um fato alegado resta suficientemente provado, o direito material impõe suas consequências ${ }^{66}$; quando não há provas suficientes, a regra do "ônus" da prova será o critério de "desempate" 67.

Discordo em dois aspectos de Ferrer Beltrán.

A primeira divergência, de ordem mais conceitual, vai no sentido de que o autor, entendendo o ônus como uma regra técnica, utiliza a categoria de ônus para o chamado "aspecto objetivo"; eu, por outro lado, - entendendo o ônus como uma situação passiva subjetiva com sujeição fraca, que descreve um comportamento (positivo ou negativo) "apreciado" pelo Direito e que dá ao sujeito sobre o qual recai a possibilidade de escolher entre o agir ou não de acordo com o comportamento (positivo ou negativo) "apreciado" - entendo que não se trata de um ônus. Diz Ferrer: "não necessitamos de regras especificas sobre o ônus da prova, mas sim da noção de ônus (objetivo) da prova"68. Em minha opinião, entretanto, não se trata propriamente de um ônus em sentido jurídico, mas sim de um dever que o sistema jurídico impõe ao juiz nos casos de insuficiência de corroboração.

A segunda, sobre a qual estou de acordo com Mitidiero ${ }^{69}$, é que, a meu ver, não há uma alteração no direito material quando se alteram as regras que impõem consequências para a insuficiência da prova. Creio que o problema do ônus dinâmico da prova é aniquilar a calculabilidade $^{70}$ (uma dimensão da segurança jurídica), pois nem o autor nem o réu podem prever de antemão qual será o resultado da demanda. Não obstante, dinâmica ou fixa, a regra do "ônus" da prova (objetivo) somente será necessária em casos de insuficiência probatória ${ }^{71}$.

O direito material seguirá sendo o mesmo, inclusive, no exemplo dado por Ferrer: diante de uma regra que estabelece que "aquele que por ação ou omissão causar dano a outrem, agindo com culpa, ou negligência, será obrigado a reparar o dano causado". Uma vez provados (i) a ação ou omissão; (ii) a culpa ou negligência e (iii) os danos, a consequência será determinada pela regra material. Se não houver prova suficiente de alguma dessas hipóteses, a regra do "ônus" da prova decidirá quem ganhará. Na minha opinião, o direito material é o mesmo; o que muda é quem perde, no âmbito processual, em caso de insuficiência probatória. E se é dado ao juiz o poder de decidir em cada caso qual será o "ônus" correspondente, cria-se uma situação de insegurança jurídica indesejável no litígio, com o que concordo com Ferrer Beltrán (discordando de Mitidiero).

\subsection{LEANDRO GIANNINI ${ }^{72}$}

Giannini expõe sua opinião sobre o tema partindo de uma crítica à jurisprudência e à doutrina argentina, pois, segundo o autor, usam "indiscriminadamente o princípio de colaboração

${ }^{64}$ PAULA RAMOS, Vitor de, op. cit., p. 88.

${ }^{65}$ FERRER BELTRÁN, Jordi, p. 72.

${ }^{66}$ PAULA RAMOS, Vitor de, cit., p. 127. De fato, não por acaso, na nota 96 daquela obra referi um debate com Jordi Ferrer, em Girona, em 14 de junho de 2013, quando a obra ainda não tinha visto a luz.

${ }^{67}$ PAULA RAMOS, Vitor de, op. cit., p. 128.

${ }^{68}$ FERRER BELTRÁN, Jordi, op. cit., p. 74, n. 44.

${ }^{69}$ MITIDIERO, Daniel, op. cit., p. 8.

${ }^{70}$ ÁVILA, Humberto. Segurança jurídica. Entre permanência, mudança e realização no direito tributário. São Paulo: Malheiros, 2011. p. 126.

${ }^{71}$ MITIDIERO, Daniel, op. cit., p. 8.

72 GIANNINI, Leandro. "Revisitando la doctrina de la 'carga dinámica de la prueba'. Aportes para esclarecer sus principales problemas conceptuales”. In: NIEVA FENOLL, Jordi; FERRER BELTRÁN, Jordi; GIANNINI, Leandro. Contra La Carga de la Prueba. Madrid: Marcial Pons, 2019. p. 23-52. 


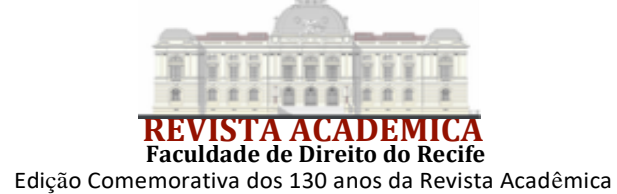

(...) e a chamada teoria do ônus dinâmico da prova"73. Após criticar a promiscuidade conceitual, o autor propõe uma distinção entre o "ônus dinâmico da prova" e a "distribuição do ônus (ou dever) de colaboração", de maneira que: (i) o "ônus de produzir provas é a manifestação do ônus da prova associada à aplicação do princípio da colaboração no processo" 74 . Nesse caso, já não se trataria, de acordo com o autor, de onerar a parte com o "peso da incerteza", senão de "exigir-lhe que coopere com o esclarecimento de certos fatos" "75; (ii) o "ônus de provar (...) seria o imperativo que incumbiria a uma parte de convencer o juiz acerca da veracidade dos fatos que alega".

A preocupação que me parece subjacente ao pensamento de Giannini, e com a qual eu concordo, é a de corrigir um dos principais problemas da doutrina do ônus dinâmico da prova: o de não separar a atividade probatória do resultado, na medida em que as "ameaças" propostas pela doutrina tradicional do ônus da prova, supostamente, apareceriam no aspecto subjetivo como consequência do aspecto objetivo - algo que gera múltiplos problemas, como o de não saber o que ocorre quando a parte não aporta uma prova que está em seu poder, mas outras provas aportadas lhe dão razão.

A isso eu acrescentaria dois pontos de confusão, além daqueles destacados por Giannini, que me parecem de grande importância: (i) que princípio e ônus não estão no mesmo plano conceitual, e (ii) que uma conduta (como a de aportar provas em seu poder ao processo), para um determinado sujeito, em um determinado sistema jurídico e momento, ou é um ônus, ou um dever. A partir de textos normativos podem ser reconstruídos três tipos de normas: postulados, regras $e$ princípios (inclusive os três tipos a partir do mesmo texto) ${ }^{76}$. Em outro plano, uma norma do tipo regra, por exemplo, pode atribuir a um sujeito um ônus ou um dever. Portanto, é de suma importância, em um sistema jurídico concreto, saber se o sujeito tem um dever de aportar provas ao processo, ou um ônus. Em outras palavras: se o sujeito está obrigado ou não, se pode ser forçado, ou não, ao cumprimento. A proposta de Giannini, não obstante, acaba tratando a colaboração como princípio $^{77}$, como "ônus (ou dever)" "78 e como dever $^{79}$; e a consequência desse dever, como um ônus, que serviria, sem embargo, seria "exigir-lhe [à parte] que coopere com o esclarecimento de certos fatos" $"$. Na minha opinião, se a parte tem o dever de colaborar (no sentido de colaboração defendido por Giannini) levando provas, já não se pode dizer, ao mesmo tempo, que tem o ônus de assim proceder.

Outra divergência com Giannini é que, ao adotar sem reservas a concepção carneluttiana de ônus (entendida genericamente como o grupo de "imperativos do próprio interesse") ${ }^{81}$, o autor acaba deixando, a meu ver, sem solução dois problemas da construção de Carnelutti ${ }^{82}$ : (i) trabalhar com a categoria de "interesse"; e (ii) ter uma concepção individualista de ônus ${ }^{83}$. Definitivamente, se o ônus é uma conduta em "interesse próprio", já não seria lógico, do meu ponto de vista, que a

\footnotetext{
${ }^{73}$ GIANNINI, Leandro, op. cit., p, 98.

${ }^{74}$ GIANNINI, Leandro, op. cit., p. 105. Como já destacou MITIDIERO, Daniel, op. cit., p. 10, a colaboração, como hoje em dia proposta no Brasil, não impõe deveres às partes, mas ao juiz; deveres como os de auxílio, de esclarecimento e de prevenção. O sistema deveria, na minha opinião, como propus, desenvolver deveres probatórios para as partes, que pudessem, inclusive, não depender do juiz (eficácia horizontal do direito fundamental à prova), ou ser "mediados" pelo juiz (eficácia horizontal mediada pela vertical do direito fundamental à prova). PAULA RAMOS, Vitor de, cit., p. 111. Sobre a colaboração, MITIDIERO, Daniel. Colaboração no Processo Civil [2009]. 4. ed. São Paulo: RT, 2010.

75 Idem, p. 105.

76 ÁVILA, Humberto. Teoria dos Princípios. Da definição à aplicação dos princípios jurídicos. 16. ed. São Paulo: Malheiros, 2015. p. 50 et seq. e 163 e et seq.

${ }^{77}$ Idem, p. 91.

${ }^{78}$ Idem, p. 99.

${ }^{79}$ Idem, p. 103.

${ }^{80} \mathrm{Idem}$, p. 105. O itálico não aparece no original.

${ }^{81}$ Idem, p. 104.

${ }^{82}$ PAULA RAMOS, Vitor de, p. 61 e et seq.

${ }^{83}$ GAVAZZI, Giacomo. L'Onere - Tra la Libertà e L'Obbligo. Torino: Giappichelli, 1970. p. 53.
} 


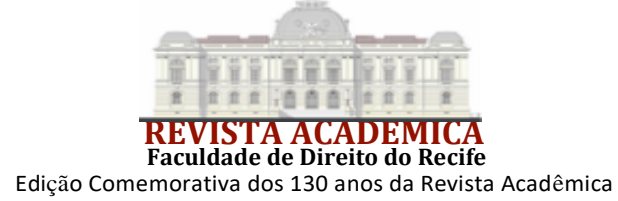

parte tivesse um dever de colaborar (para Carnelutti, o dever é uma conduta em interesse alheio) ${ }^{84}$, cuja consequência fosse um ônus de produzir provas contrárias a seu interesse; tampouco, como já dito, um ônus que pudesse ser objeto de exigência ${ }^{85}$, ou sanção ${ }^{86}$.

A meu juízo, se a parte tiver provas que favorecem a sua versão na demanda, aportará essas provas a juízo para ganhar. Não por se tratar de um ônus ou de um dever, mas sim porque tem o direito de fazê-lo. E assim procederá porque o direito assume que algo está provado quando há provas suficientes em favor da hipótese ${ }^{87}$, sendo irrelevante se as provas foram trazidas pelo autor, pelo réu, por um terceiro, ou por ordem do juiz. Para a parte que tem uma prova que lhe favorece, não é necessário falar em ônus ou deveres de aportar provas: a parte aportará a prova a juízo em razão de seu direito de produzir provas. Por outro lado, o problema surge quando a prova relevante está em poder de uma parte que não quer levar tal prova a juízo. Nesse caso, se os estímulos não são reais e concretos, e se é dada à parte a possibilidade de escolher não aportar a prova a juízo, ela não o fará.

Apesar de tudo isso, Giannini expõe um ponto que me parece importante, que é propor um ônus que tenha relação concreta com a (in)atividade da parte. Não obstante, a presunção gerada, sugerida por Giannini, seguirá sendo insuficiente para que a parte aporte uma prova que lhe prejudique: o médico que tenha um documento que demonstre algum erro seu preferirá a presunção por não aportar a prova a juízo, inclusive porque poderá derrubá-la com outras provas - de modo que segue sendo uma vantagem para a parte não aportar a prova a juízo -. Ademais, isso só poderia funcionar em um sistema em que existissem claros deveres substanciais de guarda e conservação das provas (sobre esse aspecto voltarei nas próximas partes). Caso contrário, a parte, no exemplo do médico, sempre poderá alegar que já não tem a prova, que a perdeu etc. (o mesmo acontecerá com os deveres de aporte sem deveres substanciais).

Com relação ao resultado probatório, a ideia de Giannini tem, na minha opinião, o inconveniente de que duplica os conceitos ao adotar a definição carneluttiana de ônus. Apesar de aí se estar muito mais no plano conceitual, não fica totalmente claro para mim o que aconteceria em um caso em que houvesse provas suficientes do direito do demandado, sem que este tivesse levado a cabo qualquer tipo de ação para satisfazer seu interesse probatório.

Qual seria o ônus de provar (no sentido de regra de juízo, como propõe Giannini) que o demandado cumpriria? E quando o autor aporta todas as provas que estão à sua disposição, mas o juiz, utilizando seus poderes de instrução, determina a produção de outra prova que demonstra que o réu tem a razão? Qual seria o ônus cumprido por uma parte e não cumprido pela outra?

A meu ver, a ideia de ônus proposta por Giannini tem mais relação com ônus entendido como uma necessidade prática do que com o conceito carneluttiano, individualista, adotado pelo autor. Como já assinalei, todos esses inconvenientes seriam evitados entendendo-se que o ônus de provar (o chamado "aspecto objetivo") não é um ônus processual, mas sim um dever, dirigido ao juiz (a prova é suficiente quando se alcança o standard probatório, independentemente da atividade de cada parte, ou, ao menos, sem uma relação direta ou automática).

Por último, é importante assinalar duas coisas sobre o sistema estadunidense. A primeira é que ao propor aproximar o ônus da prova dos burden of proof e os burden of producing evidence estadunidense, Giannini não menciona um aspecto que considero fundamental e que resolve muitos dos problemas relativos ao aporte de provas naquele sistema: os duties of disclosure, autênticos deveres de aportar provas relevantes, com consequências muito graves no caso de

${ }^{84}$ CARNELUTTI, Sistema del Diritto Processuale Civile. Funzione e Composizione del Processo. Padova: Cedam, 1936. p. 55. v. 1.

${ }^{85}$ Idem, p. 105.

${ }^{86}$ Idem, p 112.

${ }^{87}$ FERRER BELTRÁN, Jordi. Prueba y verdad en el Derecho. Madrid: Marcial Pons, 2005. p. 36. 


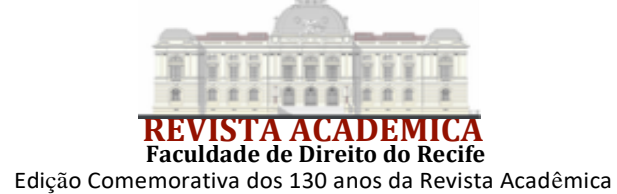

failure to disclose (previstos na Rule 37 das Federal Rules of Evidence) ${ }^{88}$. Na maioria dos casos, depois da fase de discovery, de fato, as partes, conhecendo as provas disponíveis (e os precedentes), chegam a acordos, de modo que é residual o número de casos que chegam aos trials ${ }^{89}$. Justamente porque com um autêntico dever de prova não se questiona à parte sobre se quer aportar provas a juízo; simplesmente se obriga a que o faça (dentro de limites legais e constitucionais).

O segundo ponto é que os burdens of producing evidence, no sistema estadunidense, estão pensados como etapas intermediarias de suficiência, que devem ser superadas para que o procedimento avance à fase seguinte. Nesse sentido, por exemplo, diz-se que "ao cumprir com a responsabilidade imediata imposta pelo burden of producing, o autor evita um directed verdict (que se costuma chamar de "sentença como questão de direito") e leva a disputa, pelo menos, até a fase II [resolução pelo tribunal do júri]" 90 . Por outro lado, a "ausência de satisfação do burden of producing dará lugar a uma sentença contra a parte sobre a qual recaía o burden " ${ }^{21}$. Com o caráter adversarial do sistema, ademais, o uso dos poderes de instrução do juiz na fase de trial é muito mais raro.

\subsection{DANIEL MITIDIERO ${ }^{92}$}

Mitidiero publicou, recentemente, um artigo no qual, além de reunir e resumir as ideias de Nieva Fenoll, Ferrer Beltrán, Giannini e as minhas, submete-as à crítica, formulando, em seguida, sua proposta.

Além das críticas já expostas neste artigo, Mitidiero faz três críticas principais: (i) defende a existência do ônus imperfeito: a atividade prescrita na regra que atribui o ônus seria "causa ou coeficiente que contribui em maior ou menor medida para a provável realização de um resultado"93; (ii) defende a existência do aspecto subjetivo, entendendo que esse não pode ser, com justificativa no princípio de aquisição da prova ${ }^{94}$, ignorado, uma vez que seria necessário manter o equilíbrio entre as posições do juiz e das partes de modo a "o devido relevo à liberdade das partes no que tange à conformação da sua atividade probatória e distinguir a tarefa de produzir e de valorar a prova" 95 ; (iii) defende a possibilidade de que um sistema concreto escolha regular a atividade probatória das partes mediante um ônus ou um dever.

A proposta de Mitidiero, que em parte converge com a de Giannini, vai no sentido de que as partes tenham um ônus de produzir provas e um ônus de persuasão. $\mathrm{O}$ ônus de produzir provas poderia, em um sistema concreto, conviver com (ou ser substituído por) um dever de produzir provas, mas isso não geraria um dever de persuadir. $\mathrm{O}$ autor cita o sistema brasileiro (art. 373, ônus, art. 400, dever) como um exemplo de coexistência entre os ônus e os deveres de atividade probatória. Paralelamente, Mitidiero propõe para o juiz um dever que determina "o conteúdo da

${ }^{88}$ Propondo, na Argentina, autênticos deveres de aporte de prova, vide CAZAUX, Diego. "Carga de la prueba, bases y propuestas para la reformulación del concepto. De la carga al deber de probar. Análisis crítico del caso argentino". Revista Iberoamericana de Derecho Procesal, v. 10, p. 18, 2019.

89 MCCORMICK, Charles. BROUN, Kenneth; DIX, George; IMWINKELRIED, Edward; KAYE, D. H; MOSTELLER, Robert; ROBERTS, E. F.; STRONG, John. SWIFT, Eleanor. McCormick on Evidence. 6. ed. St. Paul: Thomson West, 2006. p. 6.

${ }^{90}$ LILly, Graham. CAPRA, Daniel J. SALTZBURG, Stephen. Principles of Evidence. 5. ed. St. Paul: Thomson Reuters, 2009. p. 387-388.

91 ALLEN, Ronald; KUHNS, Richard; SWIFT, Eleanor; SCHWARTZ, David; PARDO, Michael. Evidence. Tect, Problems, and Cases. 5. ed. New York: Wolters Kluwer, 2011. p. 722.

92 GIANNINI, Leandro. "Revisitando la doctrina de la 'carga dinámica de la prueba'. Aportes para esclarecer sus principales problemas conceptuales”. In: NIEVA FENOLL, Jordi; FERRER BELTRÁN, Jordi; GIANNINI, Leandro. Contra La Carga de la Prueba. Madrid: Marcial Pons, 2019. p. 23-5.

${ }_{93}$ MITIDIERO, Daniel, op. cit.

${ }^{94}$ MITIDIERO, Daniel, p. 4

${ }^{95}$ MITIDIERO, Daniel, op. cit., p. 5 
decisão sobre os fatos em caso de dúvida" $" 96$.

Concordo com Mitidiero em muito do que propõe, inclusive em muitas das críticas expostas ao longo deste texto: com a ideia de que os sujeitos processuais podem estar submetidos a ônus ou deveres, com o dever judicial de julgar de um modo ou de outro em caso de insuficiência probatória. De fato, ao separar atividade e resultado, pode-se pensar em ônus processuais (superando o conceito carneluttiano) que introduzam incentivos reais ao aporte de provas, com a condição de que sejam estímulos reais - não a promessa vazia que propõe a doutrina tradicional ao associar "o ônus subjetivo" ao "ônus objetivo"-.

Minha divergência com Mitidiero está em dois dos três pontos mencionados e em uma proposta de esclarecimento sobre o terceiro ponto. Começarei pela defesa que faz o autor do aspecto subjetivo e os ônus imperfeitos.

Estou de acordo com Ferrer Beltrán quando afirma que não parece correto propor uma duplicação normativa da regra de juízo que impõe um dever ao juiz ${ }^{97}$. Apesar de ser perfeitamente possível que de um texto normativo se reconstruam duas regras distintas, com consequências diferentes para sujeitos diferentes, a correspondência deste dever judicial é, no âmbito das partes, um direito: o direito da parte de ganhar a causa quando não se satisfaz o standard probatório, se o risco pela falta de corroboração desses fatos é da parte contrária. Pois bem, o fato de a regra que impõe um dever ao juiz ter consequências indiretas eventuais sobre a atividade das partes não faz, a meu modo de ver, que essa tenha normatividade autônoma ${ }^{98}$ ou que seja um aspecto subjetivo dela.

A regra técnica é uma necessidade prática: "se queres ter os dentes limpos, deves escoválos", no âmbito de fora do direito; e, no âmbito jurídico, "se queres ganhar a causa, deves ter um bom advogado". Não obstante, a regra técnica, em minha opinião, não tem juridicidade autônoma ${ }^{99}$, e o ônus, como o defino, $\operatorname{sim}^{100}$. Especificamente sobre o âmbito probatório, em um processo concreto, o que faz aumentar a "probabilidade" de que uma parte ganhe ou perca uma demanda não está necessariamente em sua atividade, mas sim, no resultado que pode ser obtido a partir do conjunto probatório. Sem a regra do art. 373 do CPC, portanto, as partes, de qualquer forma, aportariam a juízo as provas que lhes favorecessem; e isso, porque teriam, ainda assim, o direito de fazê-lo, de acordo, por exemplo, com o art. 369 do CPC ${ }^{101}$.

O problema é quando não interessa à parte aportar uma prova a juízo. Vejamos o exemplo de uma pessoa cujo carro sofre danos em um estacionamento e que, nos vídeos das câmeras de segurança, se verifica que um funcionário do estacionamento fora o responsável por tais danos. Se o ato de aportar essa prova a juízo for um ônus imperfeito (no sentido de ser uma necessidade prática gerada pela regra de julgamento), a parte não aportará o vídeo a juízo. Se se utiliza um ônus invertido ou dinamizado, cujo resultado seja poder perder no futuro, seguirá sem aportar tal prova. Qual seria, então, a normatividade autônoma do ônus imperfeito de aportar provas a juízo, diferente da normatividade do art. 369? Em minha opinião, nenhuma.

O CPC brasileiro, quando prevê o ônus dinâmico da prova, certamente pretende trabalhar

${ }^{96}$ MITIDIERO, Daniel, op. cit., p. 11.

${ }^{97}$ PAULA RAMOS, Vitor de, op. cit., p. 101.

${ }^{98}$ FERRER BELTRÁN, Jordi, op. cit., p. 70, en el mismo sentido.

${ }^{99}$ FERRER BELTRÁN, Jordi, op. cit., p. 70, en el mismo sentido.

${ }^{100}$ Em minha opinião, são exemplos de ônus processuais o ônus de se defender, o ônus de recorrer, o ônus de expor a defesa de modo claro e com congruência com o que se pede etc. Por outro lado, não se trata de um ônus nem a necessidade de se ter um bom advogado, nem a necessidade de alegar incompetência absoluta (em um sistema em que o juiz deva reconhecê-la de ofício) etc., nem, como bem sustenta Jordi Ferrer, um ônus de conduzir o processo administrativo adequadamente. Na minha opinião, todas essas são hipóteses de necessidades práticas, direitos, posturas diligentes etc., mas não de ônus.

101 "Art. 369. As partes têm o direito de empregar todos os meios legais, bem como os moralmente legítimos, ainda que não especificados neste Código, para provar a verdade dos fatos em que se funda o pedido ou a defesa e influir eficazmente na convicção do juiz". 


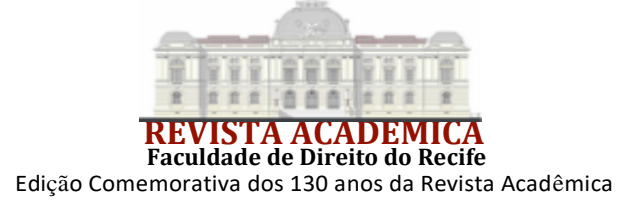

com a atividade probatória (sob meu ponto de vista, está mudando a regra de juízo para o caso de insuficiência probatória). Não obstante, em uma pesquisa jurisprudencial que fiz em 2018, o resultado, ao longo dos primeiros dois anos de vigência do CPC, foi de que o ônus dinâmico da prova só havia sido utilizado em dez ocasiões, e em nenhum desses casos a dinamização havia dado lugar ao aporte de novas provas.

Em minha opinião, isso se deve a que o "ônus" (ou ônus imperfeito) criado pelo Código, com o ônus dinâmico, apresenta uma ameaça inexistente. Ao não vincular o comportamento da parte a um resultado, não serve como verdadeiro estímulo: seguirá sendo melhor para a parte não aportar uma prova contrária ao seu interesse e correr o risco de perder, do que aportar $e$ ter a certeza disso. Mitidiero, portanto, apresenta argumentos sobre a possibilidade de utilizar o ônus dinâmico, a meu juízo, sem dar razões que sustentem seu real funcionamento como estímulo para o aumento da completude do material probatório.

Sobre o terceiro ponto, concordo com o autor: o legislador poderia, de fato, pensar em verdadeiros ônus relacionados à atividade probatória; inclusive, chegar ao limite de prever que, se a parte não aporta uma prova a juízo, a causa terminasse de imediato, perdendo a parte que não aportou a prova ${ }^{102}$. Contudo, acredito que o problema está em que, no art. 373 do CPC - o qual, segundo a doutrina, poderia ser traduzido como uma regra técnica de "se aportas mais provas, aumentas tuas possibilidades de ganhar" -, não há um verdadeiro ônus, nem um verdadeiro estímulo, porque o número de provas que uma parte aporta não faz com que essa ganhe ou perca.

O estímulo (ou nudge, como refere Mitidiero), para funcionar, deve ser real, concreto e estar conectado a uma (in)atividade da parte. As regras que impõem ônus dinâmicos, que apresentam uma ameaça com possíveis consequências futuras conectadas à regra de juízo, em minha opinião, não ajudam a melhorar a completude do material probatório, porque os nudges não são concretos: para a parte, seguirá sendo melhor não aportar uma prova contrária a seu interesse e correr o risco de perder do que aportar e ter a certeza disso. Por isso, considero que um sistema jurídico deve prever autênticos deveres de aporte de provas.

\section{COMO SEGUIR?}

Nos últimos anos, avançou-se muito no tema do chamado ônus da prova, graças a um importante debate doutrinário - infelizmente, tão raro no âmbito dos países latino-americanos-.

Um ponto que esbocei em meu trabalho de 2015/2018 e que mereceria, por parte da doutrina e das legislações, maior desenvolvimento é a necessidade de que a atividade probatória (seja para ônus, seja para deveres) encontre seus correspondentes deveres materiais no sistema, inclusive para uso extraprocessual - deveres claros, por exemplo, sobre quais documentos devem ser conservados e por quanto tempo -. Sem isso, nem com multa, nem com presunções etc. será possível saber se a parte que não leva um documento a juízo tem essa prova em seu poder, ou não. Ademais, se não há um dever material de conservação de documentos, não me parece justo (nem lícito) que isso seja exigido da parte, ou que se tirem conclusões negativas contra ela, por não ter um documento que não tinha a obrigação de conservar.

Sabendo que existe uma regra material que obriga um hospital, por exemplo, a conservar determinados documentos sobre o paciente durante cinco anos, o paciente poderia ter um direito autônomo de ter acesso a esses documentos, sem a necessidade de requerimento judicial. A perda do documento poderia gerar, também de acordo com o direito material, um dever do hospital de comunicar o fato às autoridades. Se o hospital, nesse prazo de cinco anos, não conserva o documento, nem comunica à autoridade a sua perda, isso lhe traria consequências negativas, como (em casos extremos), por exemplo, a perda de uma causa in limine, multas etc. Transcorridos os

${ }^{102}$ Em sentido parecido, sem referir-se a ônus, FERRER BELTRÁN, Jordi, “La carga dinámica...”, p. 80-81 
cinco anos, o hospital já teria o direito de se desfazer dos documentos, não sendo possível que esse viesse a sofrer qualquer consequência negativa derivada de eventual não exibição.

Desse modo, considero que tanto a doutrina quanto os legisladores de nossos países deveriam começar a debater mais sobre tal tema.

\section{CONSIDERAÇÕES FINAIS}

O propósito do presente artigo é debater com os autores que, nos últimos anos, têm escrito sobre o ônus da prova. Para finalizar, proponho algumas conclusões, algumas compartilhadas, algumas individuais:

1. Independentemente do que se defenda, é importante separar a atividade probatória do resultado.

2. Em um sistema concreto, a atividade probatória pode ser regulada mediante um direito, um ônus, ou um dever, cujas consequências serão distintas em cada caso.

3. Um processo que preveja deveres probatórios será mais eficaz em fazer com que a parte aporte a juízo provas que não são de seu interesse.

4. A regra de julgamento, o chamado "ônus objetivo", é uma regra que impõe um dever ao juiz.

5. Minha sugestão para seguir evoluindo é trabalhar e desenvolver mais a teoria sobre os deveres substanciais da prova.

\section{REFERÊNCIAS}

ALLEN, Ronald; KUHNS, Richard; SWIFT, Eleanor; SCHWARTZ, David; PARDO, Michael. Evidence. Tect, Problems, and Cases. 5. ed. New York: Wolters Kluwer, 2011.

AUGENTI, Giacomo Primo. L'Onere della Prova. Roma: Foro Italiano, 1932.

ÁVILA, Humberto. Segurança jurídica. Entre permanência, mudança e realização no direito tributário. São Paulo: Malheiros, 2011.

ÁVILA, Humberto. Teoria dos Princípios. Da definição à aplicação dos principios jurídicos. 16. ed. São Paulo: Malheiros, 2015.

CARNELUTTI, Francesco. Sistema del Diritto Processuale Civile, Funzione e Composizione del Processo. Padova: CEDAM, 1936. v. 1.

CARPES, Artur. O Ônus Dinâmico da Prova. Porto Alegre: Livraria do Advogado, 2010.

CARPES, Artur. Ônus da Prova no Novo CPC. Do Estático ao Dinâmico. São Paulo: RT, 2017.

CAZAUX, Diego. "Carga de la prueba, bases y propuestas para la reformulación del concepto. De la carga al deber de probar. Análisis crítico del caso argentino”. Revista Iberoamericana de Derecho Procesal, v. 10, 2019.

CHIOVENDA, Giuseppe. Principii di Diritto Processuale Civile. Napoli: Jovene, 1965. 


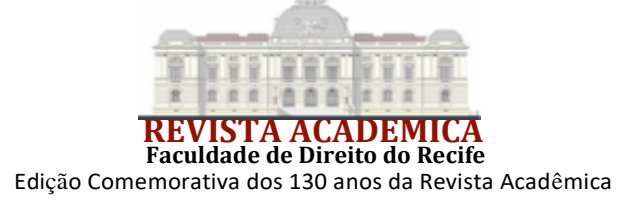

FERRER BELTRÁN, Jordi. "La carga dinámica de la prueba. Entre la confusión y lo innecesario". In: NIEVA FENOLL, Jordi; FERRER BELTRÁN, Jordi; GIANNINI, Leandro. Contra la carga de la prueba. Madrid: Marcial Pons, 2019.

FERRER BELTRÁN, Jordi. Prueba y verdad en el Derecho. Madrid: Marcial Pons, 2005.

GAVAZZI, Giacomo. L'Onere - Tra la Libertà e L'Obbligo. Torino: Giappichelli, 1970.

GIANNINI, Leandro. "Revisitando la doctrina de la 'carga dinámica de la prueba'. Aportes para esclarecer sus principales problemas conceptuales". In: NIEVA FENOLL, Jordi; FERRER BELTRÁN, Jordi; GIANNINI, Leandro. Contra la carga de la prueba. Madrid: Marcial Pons, 2019.

LILLY, Graham. CAPRA, Daniel J. SALTZBURG, Stephen. Principles of Evidence. 5. ed. St. Paul: Thomson Reuters, 2009.

MACÊDO, Lucas Buril de; PEIXOTO, Ravi. Ônus da Prova e Sua Dinamização. 2. ed. Salvador: JusPodivm, 2016.

MCCORMICK, Charles; BROUN, Kenneth; DIX, George; IMWINKELRIED, Edward; KAYE, D. H; MOSTELLER, Robert; ROBERTS, E. F.; STRONG, John; SWIFT, Eleanor. McCormick on Evidence. 6. ed. St. Paul: Thomson West, 2006.

MICHELI, Gian Antonio. L'Onere della Prova. Padova: CEDAM, 1942.

MITIDIERO, Daniel. Colaboração no Processo Civil. 4. ed. São Paulo: RT, 2010.

MITIDIERO, Daniel. “O Ônus da Prova e seus Inimigos”. Revista de Processo, v. 306, p. 17-47, ago. 2020.

MONIZ DE ARAGÃO, Egas Dirceu. "Direito à Prova". Revista de Processo, São Paulo, v. 39, p. 98 , jul. 1985.

NIEVA FENOLL, Jordi; FERRER BELTRÁN, Jordi; GIANNINI, Leandro. Contra la carga de la prueba. Madrid: Marcial Pons, 2019.

NIEVA FENOLL, Jordi. "La Carga de la Prueba: una reliquia histórica que debería ser abolida". In: NIEVA FENOLL, Jordi; FERRER BELTRÁN, Jordi; GIANNINI, Leandro. Contra la carga de la prueba. Madrid: Marcial Pons, 2019.

PAUla RAMOS, Vitor. Ônus da Prova no Processo Civil. Do Ônus ao Dever de Provar. 2. ed. São Paulo: RT, 2018.

PEYRANO, Jorge. "La carga de la prueba. Los criterios de valoración y los fundamentos de la decisión sobre quién está en mejores condiciones de probar”. In: OTEIZA, Eduardo (org.). La prueba en el proceso judicial. [Santa Fe: Rubinzal-Culzoni, 2009. 420 p.].

PICÓ I JUNOY, Joan. El juez y la prueba. Estudio de la errónea recepción del brocardo Iudex Iudicare Debet Secundum Allegata et Probata, non secundum conscientiam y su repercusión actual. Barcelona: Bosch, 2007. 
ROSENBERG, Leo. La carga de la prueba. Trad. Ernesto Krotoschin. Buenos Aires: Ediciones Jurídicas Europa América, 1956.

VERDE, Giovanni. L’Onere della Prova nel Processo Civile. Napoli: Jovene, 1974. 